Published in final edited form as:

J Agric Food Chem. 2005 May 4; 53(9): 3306-3312.

\title{
Development of a HPLC/Tandem-MS Method for the Analysis of the Larvicides Methoprene, Hydroprene, and Kinoprene at Trace Levels Using Diels-Alder Derivatization
}

\author{
Pavel A. Aronov ${ }^{\dagger}$, Katja Dettmer $^{\dagger}$, and Bruce D. Hammock ${ }^{*}, \dagger$ \\ Department of Entomology, University of California at Davis, Davis, California 95616 \\ Julie A. Christiansen $\ddagger$ and Anthony J. Cornel $¥$ \\ Mosquito Control Research Laboratory, Department of Entomology, University of California at \\ Davis, 9240 South Riverbend Avenue, Parlier, California 93648
}

\begin{abstract}
The invasion and subsequent spread of the mosquito-borne West Nile virus in the United States has resulted in increased use of methoprene. With the increased need for sensitive detection and monitoring of methoprene in the environment, an analytical LC/ESI-MS/MS method has been developed for the analysis of methoprene and two analogues, kinoprene and hydroprene, in water. To improve the ionization efficiency of the nonpolar analytes, a derivatization step with the Cooksontype reagent 4-phenyl-1,2,4-triazoline-3,5-dione (PTAD) was used. Derivatization improved the limit of detection 100-fold. For tandem MS analyses, limits of detection in environmental water samples $(\mathrm{S} / \mathrm{N}=3)$ are about $6 \mathrm{pg} / \mathrm{mL}$ for methoprene and $20 \mathrm{pg} / \mathrm{mL}$ for kinoprene and hydroprene, resulting in limits of quantification $(\mathrm{S} / \mathrm{N}=10)$ of $20 \mathrm{pg} / \mathrm{mL}$ for methoprene and $60 \mathrm{pg} / \mathrm{mL}$ for hydroprene and kinoprene extracted from $10 \mathrm{~mL}$ of water. This method was applied to measure methoprene concentrations in water samples from a treated site.
\end{abstract}

\section{Keywords}

Methoprene; kinoprene; hydroprene; West Nile virus; ESI-MS; Cookson-type reagent

\section{INTRODUCTION}

\begin{abstract}
Juvenile hormone $(\mathrm{JH})$ analogues such as methoprene, hydroprene, and kinoprene are widely used larvicides for pest control because of their negligible toxicity to vertebrates and other nontarget organisms $(1,2)$ and rapid degradation after application $(2,3)$. There has been a recent increase in methoprene application to control mosquitoes because of the spread of the West Nile (WN) virus into the U.S.A. The presence of this virus, which is transmitted by numerous mosquito species, was first detected in 1999 in New York State. By August 2004, its presence was confirmed in all states except Washington, Montana, Hawaii (4), and Alaska. Methoprene
\end{abstract}

\footnotetext{
* To whom correspondence should be addressed: Department of Entomology, University of California, Davis, CA 95616. Telephone: (530) 752-7519. Fax: (530) 752-1537. E-mail: bdhammock@ ucdavis.edu.

$\dagger$ Department of Entomology, University of California at Davis.

₹ Mosquito Control Research Laboratory, Department of Entomology, University of California at Davis.

Supporting Information Available: Derivatization kinetics and loss of instrument sensitivity in Figures A and B, respectively. This material is available free of charge via the Internet at http://pubs.acs.org.

The financial support by the National Institute of Environmental Health Sciences, Grants R37 ES02710, P42 ES04699, 1 P01 ES11269, and U01 AI058267, USDA Competitive Research Grant 2003-35302-13499, and the German Research Foundation are gratefully acknowledged.
} 
is currently one of the few approved pesticides used to efficiently control aquatic stages of mosquitoes. Extensive methoprene use requires sensitive and robust analytical tools to monitor postapplication concentrations and presence.

Several analytical methods including GC/MS (2), GC/FID (3), and HPLC/UV (5) have been used for methoprene analysis. Linking liquid chromatography with mass spectrometry (LC/ MS) often improves the selectivity and sensitivity that allows the simplification of the sample preparation and analysis. Methoprene analysis using electrospray ionization and singlequadrupole MS detection has already been reported by Wang et al. (6); however, because of the nonpolar nature of methoprene, its ionization efficiency in the electrospray process is low. In addition, single-quadrupole MS detection may not provide sufficient selectivity and sensitivity for reliable environmental sample analysis.

In the current study, an analytical method for methoprene detection and quantification is described. The method includes HPLC separation, electrospray ionization in positive mode, and tandem mass spectrometry using selected reaction monitoring.

However, electrospray ionization and tandem MS detection of methoprene lacks the sensitivity necessary for trace analysis in environmental samples because of its insufficient ionization efficiency in the electrospray process. Derivatization was, therefore, used in this work to enhance the sensitivity. Diels-Alder cycloaddition represents one way to make methoprene more readily ionizable. Methoprene contains a diene structure, which is able to undergo a $4+2$ Diels-Alder cycloaddition with appropriate dienophiles at room temperature.

The Cookson-type reagent 4-phenyl-1,2,4-triazoline-3,5-dione (PTAD), previously reported in vitamin D analysis $(7,8)$, is used for analyte derivatization (Figure 1). PTAD readily reacts with the diene group of methoprene and other JH analogue pesticides (Figure 1). The derivative contains a proton-accepting amide group facilitating positive-mode electrospray ionization. In addition, the higher mass of the derivatized analytes allows better mass spectrometric analysis because of the lower background. In addition to the optimization of HPLC separation and mass spectrometric detection, a procedure for solid-phase extraction has been developed and applied to extract methoprene from water samples.

Resistance to methoprene had been reported in the mosquito Ochlerotatus nigromaculis (Ludlow) from other locations approximately 15 miles northeast of the field site in Riverdale (9), and a year later mosquito abatement personnel were concerned that resistance had spread despite their attempts to curtail it. Consequently, a field trial was conducted to determine methoprene susceptibility profiles of these mosquitoes and to evaluate the sensitivity of the newly developed method for methoprene analysis from water samples taken from this field pre- and post-treatment.

\section{MATERIALS AND METHODS}

\section{Chemicals}

$(S)$-Methoprene, $(S)$-kinoprene, and $(S)$-hydroprene were kindly provided by Welmark International (Dallas, TX). Stock solutions of the pesticides were prepared weekly in methanol and kept in the dark at $+4{ }^{\circ} \mathrm{C}$. PTAD was purchased from Fluka (Milwaukee, WI). Methanol, ethyl acetate, and acetonitrile used for extraction and HPLC separation, and sodium azide, were purchased from Fisher Scientific (Pittsburgh, PA). All solvents were HPLC-grade. Water solutions were prepared with deionized water (resistivity of $18.1 \mathrm{M} \Omega / \mathrm{cm}$ ).

At the field site, (Riverdale, Fresno County, CA) Altosand (Zoecon division of Wellmark International, Dallas, TX) with 5\% S-methoprene was prepared and applied at maximum 
application rates according to the instructions of the manufacturer (9) when the mosquitoes were in late 3rd and early 4th stages.

\section{Water Samples}

Water samples were collected from 13 preselected sites prior to Altosand application and from the same 13 sites again immediately after application at 2 p.m. (day 1). Additional samples were collected at 2 p.m. each day for 4 days post-treatment. Altosand was applied at 8 of those 13 preselected sites and 5 sites were left untreated as controls. Individual samples were collected in $138 \mathrm{~mL}$ amber glass bottles (Fisher Scientific, Pittsburgh, PA) according to standard methodology (10) and preserved with $10 \%$ methanol and $0.02 \%$ sodium azide. Samples were kept at $4{ }^{\circ} \mathrm{C}$ prior to analysis.

\section{Solid-Phase Extraction}

Prior to extraction, $38 \mathrm{~mL}$ aliquots of water samples were removed for storage and the remaining $100 \mathrm{~mL}$ aliquots in the bottles were spiked with $10 \mu \mathrm{L}$ of $44 \mu \mathrm{g} / \mathrm{mL}$ kinoprene in methanol. The bottles were shaken vigorously for $1 \mathrm{~min}$, and $10 \mathrm{~mL}$ aliquots were taken for SPE extraction. SPE extraction was performed using Oasis HLB $3 \mathrm{~cm}^{3}(60 \mathrm{mg})$ extraction cartridges (Waters, Milford, MA). Prior to sample application, the cartridges were activated with $2 \mathrm{~mL}$ of methanol followed by $2 \mathrm{~mL}$ of water. After sample extraction, the cartridges were washed with $3 \mathrm{~mL}$ of water and the analytes were eluted with $2 \mathrm{~mL}$ of ethyl acetate into $4 \mathrm{~mL}$ collecting glass vials (Fisher Scientific, Pittsburgh, PA). Each water sample was extracted in four replicates, and extracts were stored at $-80^{\circ} \mathrm{C}$. The SPE method was shown to yield high recovery of the 3 analytes, but it was not optimized to minimize possible matrix effects.

\section{Derivatization}

Ethyl acetate extracts were evaporated under a gentle stream of nitrogen at room temperature, and $200 \mu \mathrm{L}$ of $750 \mu \mathrm{g} / \mathrm{mL}$ PTAD in acetonitrile were added to the vials. The vials were vortexed for $1 \mathrm{~min}$, and then $100 \mu \mathrm{L}$ of the sample was transferred to $150 \mu \mathrm{L}$ glass inserts (Waters, Milford, MA) in $2 \mathrm{~mL}$ amber HPLC vials (Fisher Scientific, Pittsburgh, PA). Samples were allowed to react at room temperature for $1 \mathrm{~h}$ after PTAD was added.

\section{LC and MS Conditions}

Chromatographic separation was performed using a Waters 2790 separation module (Waters, Milford, MA) equipped with a $150 \times 2.00 \mathrm{~mm}$ Hypersil $3 \mu \mathrm{m}$ C18-BD column (Phenomenex, Torrance, CA) held at $20^{\circ} \mathrm{C}$. A solvent system consisting of water with $0.1 \%$ formic acid (solvent A) and acetonitrile with $0.1 \%$ formic acid (solvent B) was used. The analytes were separated using a gradient program $(0.2 \mathrm{~mL} / \mathrm{min})$ starting with a solvent composition of $80 \%$ solvent B, held for $2 \mathrm{~min}$, and then ramped using a linear gradient for $8 \mathrm{~min}$ to $100 \%$ solvent $\mathrm{B}$, held for $2 \mathrm{~min}$ (Figure 2). The injection volume was $10 \mu \mathrm{L}$. The samples were kept at $10^{\circ}$ $\mathrm{C}$ in the autosampler.

Analytes were detected by electrospray ionization in positive mode, tandem quadrupole mass spectrometry in multiple reaction monitoring mode (MRM) using a Quattro Ultima tandem quadrupole mass spectrometer (Micromass, Manchester, U.K.). Nitrogen gas flow rates were fixed with a cone gas flow of $125 \mathrm{~L} / \mathrm{h}$ and a desolvation gas flow of $700 \mathrm{~L} / \mathrm{h}$. Electrospray ionization was performed in positive mode with a capillary voltage fixed at $3.00 \mathrm{kV}$ and a cone voltage fixed at $30 \mathrm{~V}$ using a source temperature of $125^{\circ} \mathrm{C}$ and a desolvation temperature of $350^{\circ} \mathrm{C}$. Capillary and cone voltage were optimized in an infusion experiment (data not shown). Argon was used as collision gas $\left(2.3 \times 10^{-3}\right.$ Torr $)$. Optimum collision voltages were determined experimentally by acquisition of product ion spectra (Table 1). These spectra were used to select a dominant product ion to set up the transition monitored in the MRM mode. 


\section{Quantification}

Selected ion chromatograms were integrated using the QuantLynx module of the MassLynx 4.0 software (MicroMass, Manchester, U.K.). The methoprene concentration was normalized to the kinoprene concentration. Final methoprene concentration in water sample $\left(C_{\text {meth }}^{\text {env }}\right)$ was calculated as

$$
C_{\mathrm{meth}}^{\mathrm{env}}=C_{\mathrm{meth}}^{\mathrm{exp}} \frac{C_{\mathrm{kyn}}^{\mathrm{theor}}}{C_{\mathrm{kyn}}^{\exp }} D \omega
$$

where $D$ is a ratio of the original extracted water volume to final LC sample volume (concentration factor), $\omega$ is a dilution of original water sample with methanol (methanol dilution factor), $C_{\mathrm{meth}}^{\mathrm{exp}}$ and $C_{\mathrm{kyn}}^{\exp }$ are concentrations of methoprene and kinoprene experimentally found in a concentrated sample, and $C_{\mathrm{kyn}}^{\text {theor }}$ is the theoretical kinoprene concentration from the added internal standard in a concentrated sample. The values of $D$ and $\omega$ were constant for all samples and equal $50(10.0 \mathrm{~mL} / 0.2 \mathrm{~mL})$ for $D$ and $(138.0 \mathrm{~mL} / 124.5 \mathrm{~mL} \approx 1.1)$ for $\omega$. Experimental concentrations of methoprene and kinoprene were quantified using external standard calibration. Calibration curves for both compounds contained five points from 0.3 to $30.0 \mathrm{ng} /$ $\mathrm{mL}$ and were linear.

\section{Mosquito Sampling and Susceptibility Assays}

Before methoprene was applied to the pasture, 1st and 2nd stage larvae were collected and reared in the laboratory to the 4th stage for bioassays (11). In addition, to compare mortality observed in the laboratory assays, pupae were collected from several locations at the same pasture including the five pools of water from which water samples were taken for methoprene quantification.

\section{RESULTS AND DISCUSSION}

\section{Derivatization Procedure}

In a preliminary experiment, the derivatization efficiency and kinetics of the Diels-Alder reaction (Figure 1) were investigated by online monitoring of derivative formation using highresolution time-of-flight mass spectrometry (TOF-MS, LCT, Micromass, Manchester, U.K.). The PTAD and pesticide concentrations were $166 \mu \mathrm{g} / \mathrm{mL}$ and $41.6 \mathrm{ng} / \mathrm{mL}$ (7000:1 molar ratio). The reaction mix was continiously infused in the TOF-MS detector, and $[\mathrm{M}+\mathrm{H}]^{+}$ions of derivatized and nonderivatized pesticides were monitored. Peak heights of the ions were acquired every $10 \mathrm{~min}$ and averaged over $1 \mathrm{~min}$ intervals. Methoprene, kinoprene, and hydroprene were completely converted into the corresponding derivatives in about $1 \mathrm{~h}$ at room temperature (see Figure A in the Supporting Information). In methoprene, the diene is conjugated to the ester, and therefore, it is much less reactive than a diene lacking conjugation to an electron-withdrawing group. To prevent possible loss of PTAD because of the reaction with more reactive dienes present in water samples, the final PTAD concentration was increased to $750 \mu \mathrm{g} / \mathrm{mL}$ for derivatization of environmental samples. The increase of the PTAD concentration did not affect the noise level in the chromatograms (data not shown).

\section{Optimization of the MS Parameters}

To develop a specific and sensitive method for the analysis of methoprene, selective reaction monitoring was chosen as an operating mode for the tandem mass spectrometer. Optimum cone voltages for the formation of the precursor ions and preferable molecular ions $[\mathrm{M}+\mathrm{H}]^{+}$, during electrospray ionization, were determined by infusion of derivatized and nonderivatized analytes into the mass spectrometer. The derivatized analytes exhibited the highest ionization 
efficiency in positive mode, probably because of the nitrogen introduced in the molecule after derivatization (Figure 3). The nonderivatized analytes also were ionized in the positive mode and showed no ion formation in the negative mode. Methoprene-PTAD undergoes decomposition in the ionization source producing the very abundant decomposition ion $[\mathrm{M}$ $+\mathrm{H}-32]^{+}$caused by a loss of methanol (Figure 3 ). This ion was chosen as a precursor ion for methoprene-PTAD detection. Product ion spectra of nonderivatized and derivatized analytes using the molecular ions and $[\mathrm{M}+\mathrm{H}-32]^{+}$for methoprene, respectively, as the precursor ion, were acquired (Figure 4). Fragmentation patterns of the derivatized analytes were similar (Figure 4). A characteristic ion with $\mathrm{m} / \mathrm{z} 242$ was found in all spectra, and the putative structure of the ion is shown in Figure 4. Similar ions were observed for PTAD derivatives of vitamin $\mathrm{D}_{3}$ synthetic analogues in the $\mathrm{MS}^{2}$ fragmentation experiment (8). Thus, fragmentation of methoprene and vitamin D derivatives does not involve retro Diels-Alder. This ion was chosen as a representative product ion for all PTAD derivatives in tandem MS experiments. The optimized detection parameters are shown in Table 1. The formation of a common product ion for PTAD derivatives could be used in the future to develop a tandem MS-based method to screen for compounds containing a diene structural unit.

\section{Calibration Curve}

Calibration curves were obtained for analytes based on chromatographic separation of the standards with detection conditions described above. For nonderivatized compounds, calibration curves were linear from 300 to $20000 \mathrm{pg}$ per compound injected onto the column. Derivatization resulted in about 3 orders of magnitude sensitivity increase for methoprene and 2 orders of magnitude sensitivity increase for kinoprene and hydroprene (Table 1). Higher sensitivity for methoprene is due to high abundance of its [M+H-32] $]^{+}$insource decomposition ion, which was selected as a precursor ion. Calibration curves were linear in the range of 3$300 \mathrm{pg}$ of analytes applied on the column. The highest sensitivity was obtained for methoprenePTAD; however, it had also the highest variability, which resulted in the lowest $R^{2}$ values. This variability is probably due to a less reproducible decomposition of methoprene-PTAD in the ionization source.

\section{Extraction Procedure}

Surface water from Putah Creek was used to develop the SPE protocol. Water was spiked with known amounts of methoprene, kinoprene, and hydroprene and applied to the extraction cartridges. Volumes of 10,20 , and $30 \mathrm{~mL}$ of water containing 1, 2, and $3 \mathrm{ng}$ of each analyte, respectively, were extracted. The cartridges were eluted twice with $2 \mathrm{~mL}$ of ethyl acetate. The experiments were performed in triplicates. The recovery experiments showed that more than $95 \%$ of the relative amounts of the analytes were eluted in the first $2 \mathrm{~mL}$ of ethyl acetate (data not shown).

Sample concentration under a nitrogen blanket at room temperature and transfer of the analytes from collecting vials into HPLC vials resulted in absolute losses of $41 \pm 15 \%$ methoprene, 62 $\pm 6 \%$ kinoprene, and $58 \pm 10 \%$ hydroprene, respectively $(n=3)$. Addition of pentadecane as an analyte trap prior to ethyl acetate evaporation under nitrogen blanket and solvent evaporation with RC10.22 Speedvac concentrator (Jouan, Winchester, VA) did not improve analyte recovery significantly (data not shown). However, solvent evaporation in a Speedvac was 4 times faster and did not require nitrogen. Therefore, speedvac evaporation can be used as an alternative sample concentration technique.

Further investigation showed that analyte losses during transfer were probably due to absorption on the walls of glass vessels. To circumvent this problem, kinoprene was used as an internal standard for methoprene analysis because it is similar in structure and has the most similar retention properties on the reversed-phase column used in the experiments. 
One of the major problems encountered in the analysis of methoprene is the susceptibility of the analyte to bio- and photodegradation as well as its adsorption at the glass walls of the sampling vessel. The influence of temperature, biodegradation, photodegradation, and adsorption was studied in a 3 day trial study to develop a protocol for handling of the samples. Amber glass bottles with the caps lined on the inside with aluminum foil were filled with Puta Creek water containing $0.02 \%$ sodium azide and $10 \%$ (volume) methanol. These trial samples were spiked with the mix of the analytes $\left(100 \mathrm{pg} / \mathrm{mL}\right.$ of each) and were kept at $+4{ }^{\circ} \mathrm{C}$ in a refrigerator for 3 days. The influence of deviations from this protocol was studied; therefore, one bottle was kept at the strict protocol conditions, while others were kept with omission of several storage parameters (one bottle per experiment). On the third day, samples were extracted in triplicates as described above. As a control of recovery, a freshly prepared solution of analytes $(100 \mathrm{pg} / \mathrm{mL}$ of each) in water with $10 \%$ (volume) methanol was used. The results are summarized in Table 2.

Samples must be stored at $+4{ }^{\circ} \mathrm{C}$ in the dark prior to analysis. Sodium azide addition and amber glass bottles did not prevent analyte decomposition at room temperature and ambient light exposure. Aluminum foil lining the cap of the bottle significantly reduces the loss of analytes because of the prevention of adsorption to the plastic cap.

\section{Analysis of Environmental Samples and Method Validation}

A decrease in sensitivity was observed while running a sequence of 200 samples. This was assessed by a comparison of the chromatographic peak area of the internal standard (kinoprene) (see Figure B in the Supporting Information). Sensitivity decreased around 10-fold during analysis of the first 50 samples and then remained stable for the rest of the sequence. The loss of sensitivity was probably due to the accumulated residue on the sample cone and hexapoles.

For a conservative evaluation of the instrument performance, it is therefore practical to estimate the instrumental limits of detection (LOD) and quantification (LOQ) when the instrumental sensitivity is stable though moderate. Sample LOD and LOQ were estimated by determining minimal concentrations of calibration standards resulting in chromatographic peaks with a signal-to-noise ratio $\geq 3$ (LOD), and 10 (LOQ), respectively, and divided by a factor of 50 because water samples were 50-fold concentrated. Signal-to-noise ratios were calculated as root-mean-squared values using MassLynx 4.0 software (MicroMass, Manchester, U.K.). Conservative estimates of LOD and LOQ are shown in Table 3. If the deterioration in signal could be prevented, the sensitivity of the method would be more than 5 times higher. It should be noted that signal deterioration does not affect quantification because the internal standard was used, which corrects this effect. The sensitivity of the reported method is 1 order of magnitude higher than that of the standard GC/MS-based method (2).

Although tandem mass spectrometers may not always be available in the laboratory because of their high costs, the reported derivatization approach can also be applied with other mass spectrometers using electrospray ionization including single-quadrupole instruments. A comparative study was performed to evaluate performance of a single-quadrupole instrument. Methoprene standards were dissolved in pure acetonitrile as well as in the extract from Putah Creek water matrix (extracted as described above). These two groups of samples were analyzed in MRM and SIR (single-ion recording) modes using a Quattro Ultima tandem quadrupole mass spectrometer (Micromass, Manchester, U.K.). The latter mode is analogous to SIR acquisition using a single-quadrupole instrument. Table 4 shows the results for methoprenePTAD at $10 \mathrm{ng} / \mathrm{mL}$ concentration (100 pg injected on the column). Signal-to-noise ratios and peak areas were calculated using MassLynx 4.0 software as described above (MicroMass, Manchester, U.K.). Although the absolute value of analyte signal is higher in SIR mode, MRM mode provided a superior signal-to-noise ratio and lower background level, especially if the 
analyte is dissolved in the complex matrix. With sample preconcentration using a SPE column, a single-quadrupole instruments may provide reasonable sensitivity for derivatized analytes.

Derivatization destroys the conjugated diene chromophore group of the analytes (Figure 6); therefore, they are not optimum for HPLC with UV detection. However, a PTAD analogue with a chromophore group could be synthesized to improve method sensitivity. Fluorescent analogues of PTAD such as the commercially available 4-[4-(6-methoxy-2-benzoxazolyl) phenyl]-1,2,4-triazolidine-3,5-dione (MBOTAD) can be used for detection of methoprene derivatives by HPLC using a fluorescence detector (12).

Operationally significant tolerance (resistance) to methoprene was detected in $O$. nigromaculis mosquitoes from the Riverdale site. Mortality of only $26.1 \%$ was recorded from field-collected pupae, and from susceptibility assays, $\mathrm{LD}_{30}, \mathrm{LD}_{50}$, and $\mathrm{LD}_{90}$ of $1.14,15.9$, and $9.9 \mathrm{ng} / \mathrm{mL}$ were recorded, respectively. Probit analysis on the susceptibility assays produced an $\mathrm{LD}_{26}$ confidence interval (95\%) of $0.07-6.83 \mathrm{ng} / \mathrm{mL}$. Consequently, we would expect that the concentration of methoprene in the field $24 \mathrm{~h}$ after application when larvae were in the 4th stage (stage for methoprene action) should fall within this range. The methoprene concentration determined in environmental water samples from the field experiment are shown in Table 5. Each water sample was analyzed in four replicates. The reproducibility of the analysis was acceptable with average relative standard deviations of $12 \%$. Methoprene was not detected in the samples collected before Altosand application and in the samples from five control sites. The rapid decline in methoprene concentration after Altosand application was expected because this formulation is not designed to have residual activity and methoprene is known to rapidly degrade under direct sunlight, high temperatures, and "microbially" rich waters (3, 13), characteristic of conditions in California animal pastures.

Methoprene concentrations although variable from site to site all fell within the predicted range $(0.07-6.83 \mathrm{ng} / \mathrm{mL})$, which suggests that our susceptibility assays show correlations with field situations. One would realistically expect variations in methoprene concentrations across an irrigated pasture. Uniform applications of Altosand (numbers of sand granules falling per square area) are difficult because of the pure mechanics of maintaining a constant speed on rough terrain and maintaining constant numbers of sand granules flung out from the vehiclemounted seeder. Furthermore, because pastures are not uniformly flat and have uneven vegetation coverage, flood-irrigated water immediately unevenly evaporates because of variable shading and uneven seepage through the substrate. Consequently, pools of variable depth form, and methoprene-contaminated water is unevenly drawn into areas of lowest depression (deeper pools) within the first $24 \mathrm{~h}$ after flooding.

Control environmental samples from five nontreated sites where methoprene was not detected were spiked in a blind fashion with methoprene of known concentrations in a range from 0.83 to $8.33 \mathrm{ng} / \mathrm{mL}$ and subjected to the same analytical protocol. Spiked methoprene concentrations are within the confidence limit at a 95\% probability level (Figure 5).

Derivatization of methoprene, kinoprene, and hydroprene with the Cookson-type reagent PTAD significantly improved the sensitivity of the analytical method based on electrospray ionization in positive mode. The high sensitivity allows us the use of small sample volumes $(10 \mathrm{~mL})$ for the analysis of evanescent $\mathrm{JH}$ analogue larvicides in environmental water samples and can be used as an alternative to the previously reported high-volume liquid-liquid extraction method (2).

\section{Supplementary Material}

Refer to Web version on PubMed Central for supplementary material. 


\section{ACKNOWLEDGMENT}

We thank Kathleen Thornton (Wellmark International, TX) for providing the pesticide standards, Steve Mulligan III (manager of the Consolidated Mosquito Abatement District) for methoprene field application, as well as George Lindahl (Wellmark International, TX), John Newman, Paul Jones, and Theresa Pedersen (Department of Entomology, University of California at Davis) for the valuable discussions.

\section{LITERATURE CITED}

1. Degitz SJ, Durhan EJ, Tietge JE, Kosian PA, Holcombe GW, Ankley GT. Developmental toxicity of methoprene and several degradation products in Xenopus laevis. Aquat. Toxicol 2003;64:97-105. [PubMed: 12763670]

2. Henrick CA, Ko J, Nguyen J, Burleson J, Lindahl G, Van Gundy D, Edge JM. Investigation of the relationship between $S$-methoprene and deformities in anurans. J. Am. Mosq. Control Assoc 2002;18:214-221. [PubMed: 12322945]

3. Ross DH, Judy D, Jacobson B, Howell R. Methoprene concentration in freshwater microcosms treated with sustained-release Altosid formulations. J. Am. Mosq. Control Assoc 1994;10:202-209.

4. Centers for Disease Control and Prevention. Morbidity and Mortality Weekly Report 53:742-743.

5. Abu-Qare AW, Abou-Donia MB. A solid-phase extraction reversed-phase HPLC method for the simultaneous determination of methoprene, permethrin, and selected metabolites in rat plasma and urine. Biomed. Chromatogr 2001;5:464-470. [PubMed: 11746243]

6. Wang I-S, Moorman R, Burleson J. Isocratic reversed-phase liquid chromatographic method for the simultaneous determination of $(S)$-methoprene, MGK264, piperonyl butoxide, sumithrin, and permethrin in pesticide formulation. J. Chromatogr., A 2003;983:145-152. [PubMed: 12568378]

7. Higashi T, Miura K, Kikuchi R, Shimada K, Hiyamizu H, Ooi H, Iwabuchi Y, Hatakeyama S, Kubodera N. Characterization of new conjugated metabolites in bile of rats administered 24,25-dihydroxyvitamin $\mathrm{D}_{3}$ and 25-hydroxyvitamin $\mathrm{D}_{3}$. Steroids 2000;65:281-294. [PubMed: 10751640]

8. Weiskopf AS, Vouros P, Cunniff J, Binderup E, Bjoerkling F, Binderup L, White W-C, Posner GH. Examination of structurally selective derivatization of vitamin $\mathrm{D}_{3}$ analogues by electrospray mass spectrometry. J. Mass Spectrom 2001;36:71-78. [PubMed: 11180648]

9. Cornel AJ, Stanich MA, Farley D, Mulligan FS, Byde G. Methoprene tolerance in Aedes nigromaculis in Fresno County, California. J. Am. Mosq. Control Assoc 2000;16:223-228. [PubMed: 11081650]

10. Guide to Sampling Air, Water, Soil, and Vegetation for Chemical Analysis. Sacramento, CA: 1994. State of California, Environmental Protection Agency, Department of Pesticide Regulation, Environmental Monitoring and Pest Management Branch, Environmental Hazards Assessment Program; p. 7-10.

11. Cornel AJ, Stanich MA, McAbee RD, Mulligan FS. High level methoprene resistance in the mosquito Ochlerotatus nigromaculis (Ludlow) in central California. Pest Manage. Sci 2002;58:791-798.

12. Shimada K, Mizuguchi T. Sensitive and stable Cookson-type reagent for derivatization of conjugated dienes for high performance liquid chromatography with fluorescence detection. J. Chromatogr 1992;606:133-135.

13. Schaeffer CH, Dupras EF. Insect development inhibitors. 4. Persistence of ZR-515 in water. J. Econ. Entomol 1973;66:923-925. [PubMed: 4732614] 


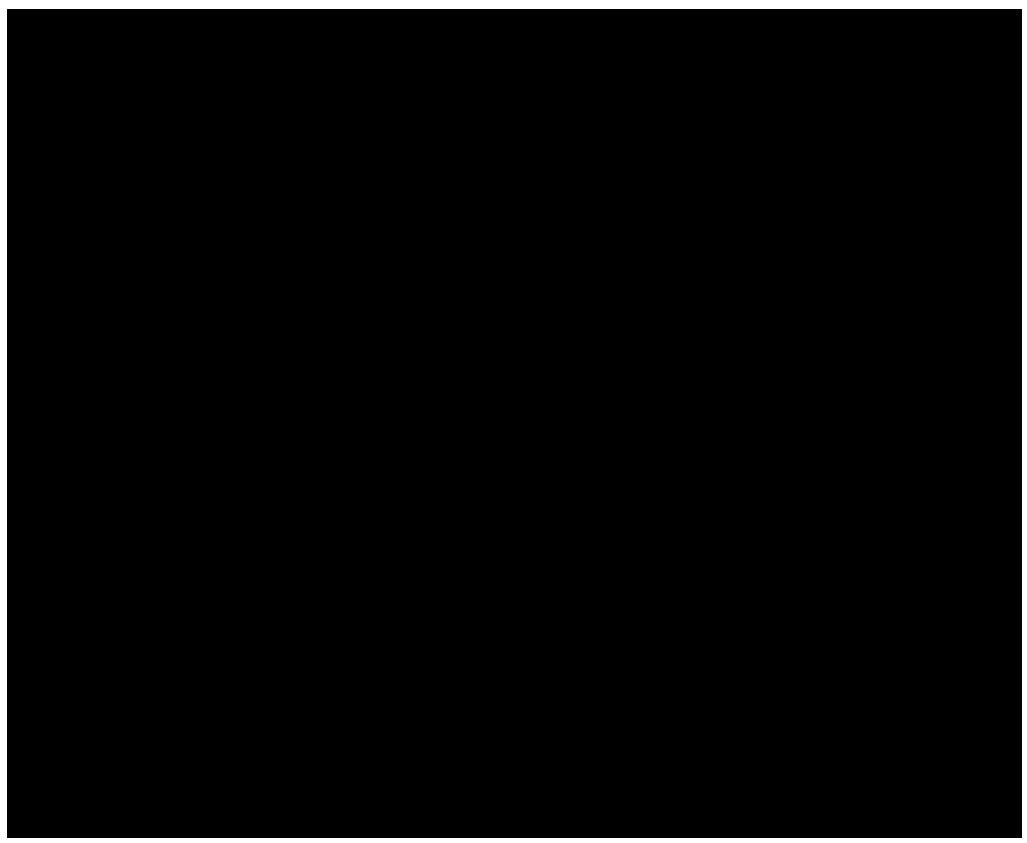

Figure 1.

Derivatization reaction. 


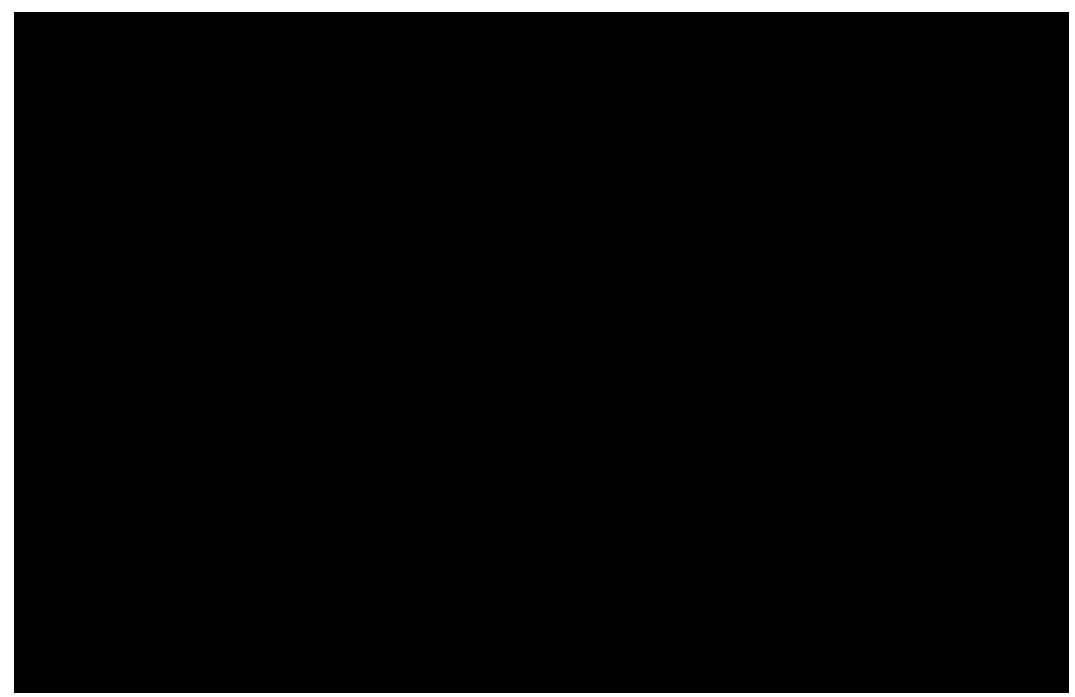

Figure 2.

HPLC separation of a standard mixture under optimum conditions withMS detector (MRM mode) [5 ng/mL, $10 \mu \mathrm{L}$ injected]. (A) Methoprene-PTAD. (B) Kinoprene-PTAD. (C) Hydroprene-PTAD. 


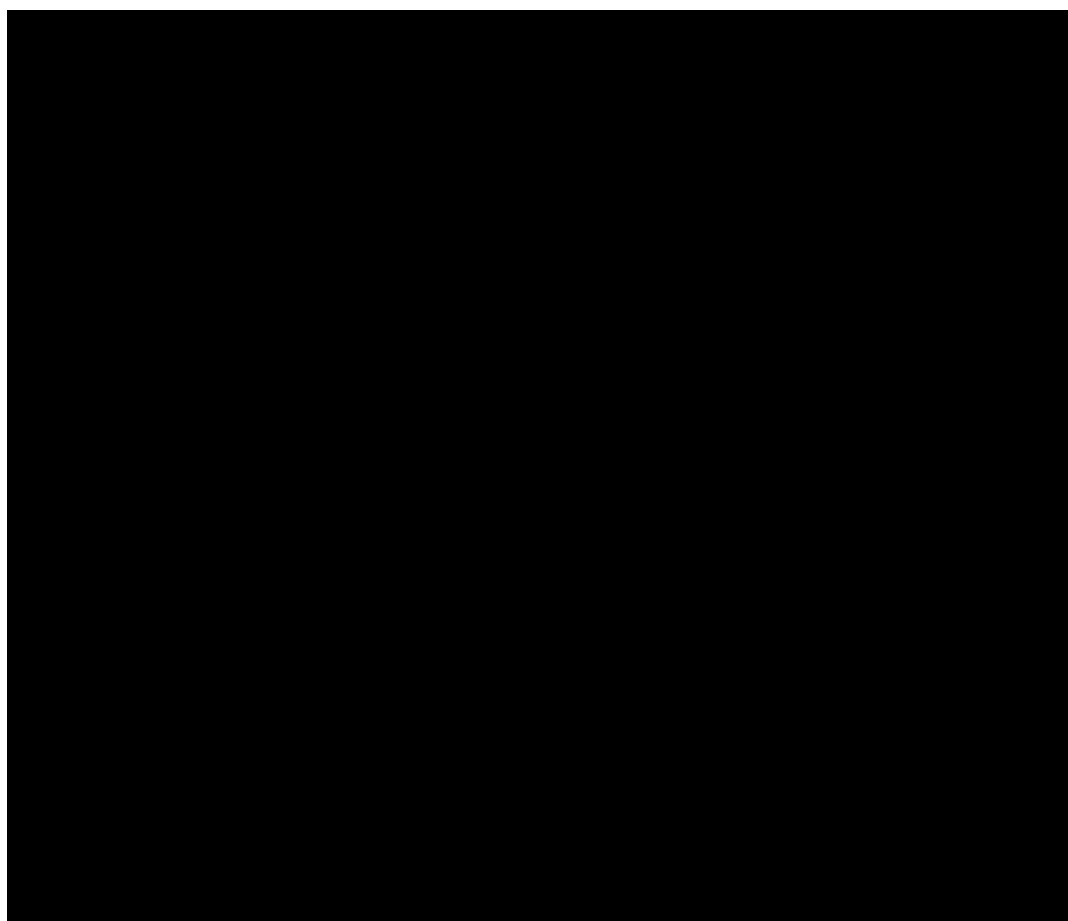

Figure 3.

Full-scan spectrum of an analyte mix. Molecular masses of nonionized (nonprotonated) analytes are shown. 


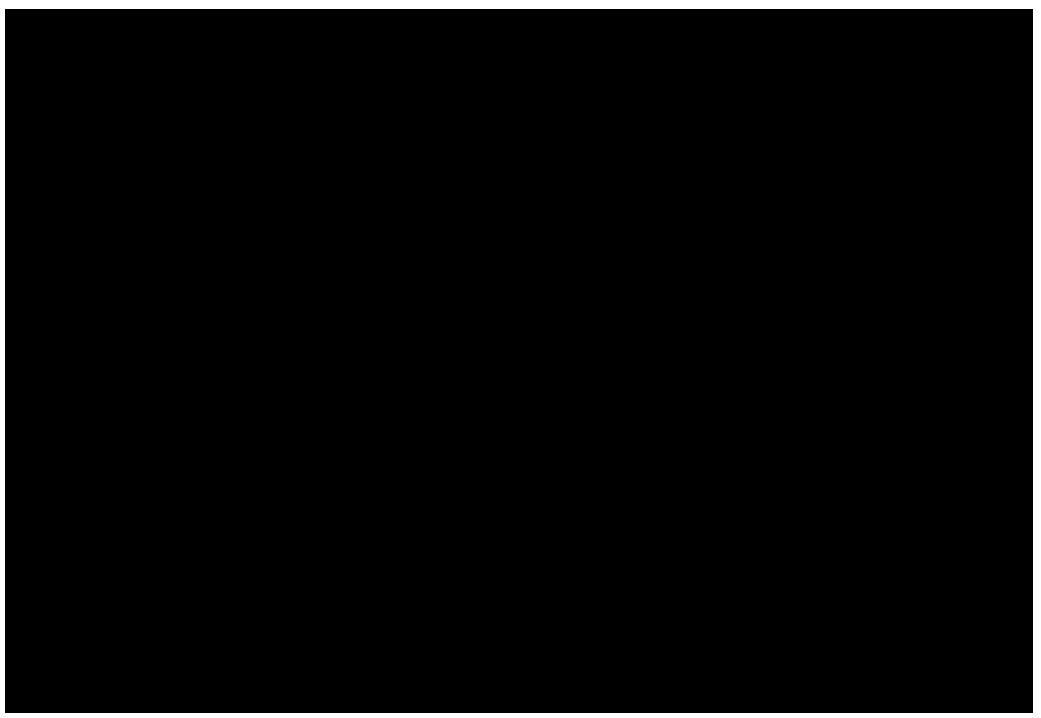

Figure 4.

Daughter ion spectra. (A) Methoprene-PTAD. (B) Kinoprene-PTAD. (C) HydroprenePTAD. In spectrum A, putative fragmentation of the analytes and formation of the common product ion is shown. Charge position in the molecules is arbitrary. 


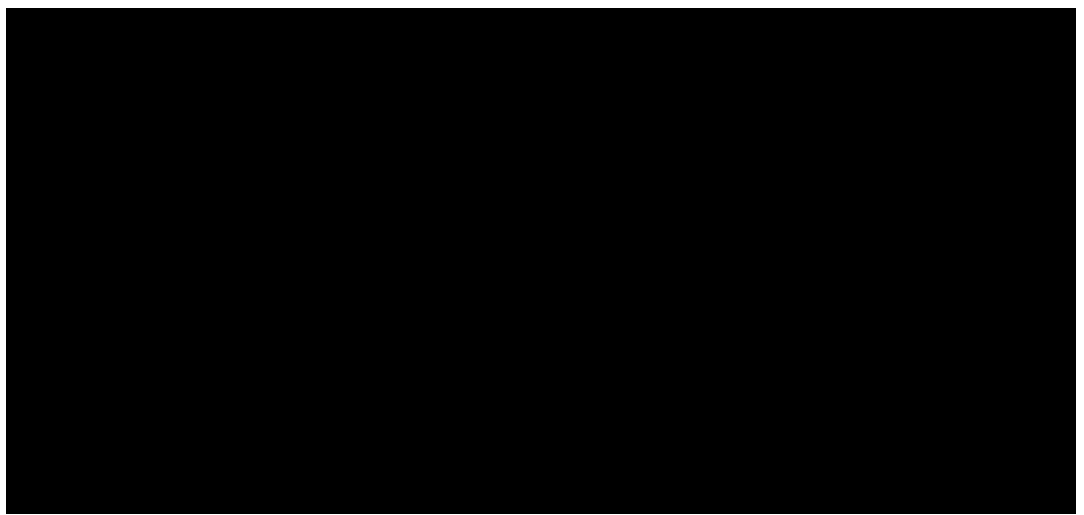

Figure 5.

Method validation. Analysis of environmental water samples spiked with known concentrations of methoprene and kinoprene (internal standard). White bars, experimental values; black bars, theoretical values. Error bars represent confidence intervals at a 95\% probability level. 


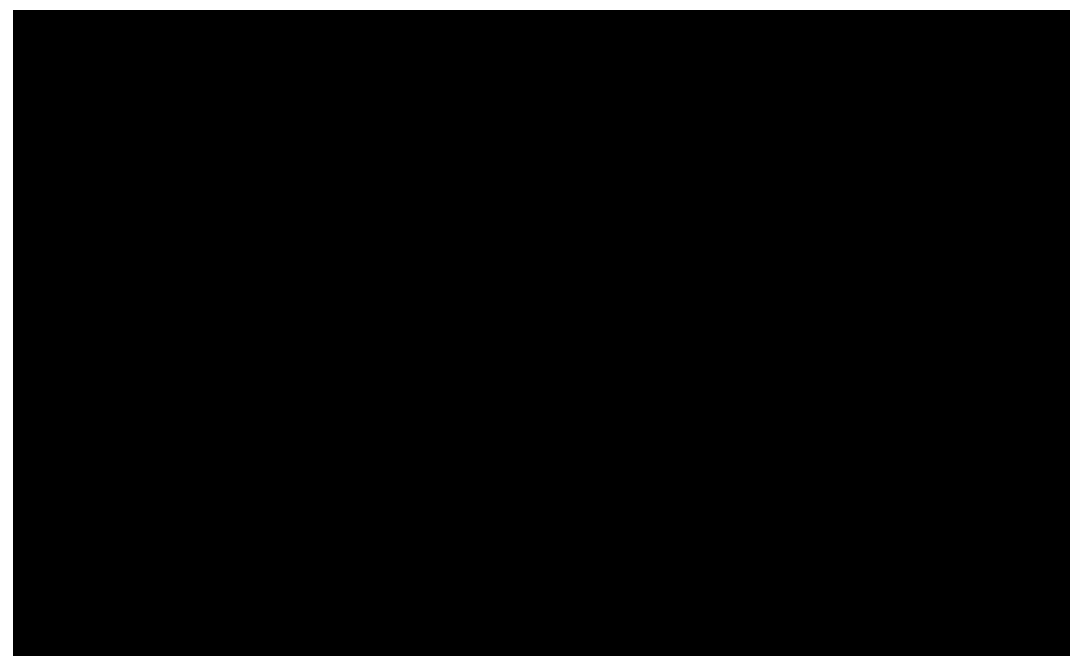

Figure 6.

UV spectra of derivatized and nonderivatized methoprene. (1) Derivatized methoprene. (2) Nonderivatized methoprene. Spectra were acquired using Waters 2996 Photodiode Array Detector (Waters, Milford, MA). 
Table 1

Mass Spectrometry Detection Parameters and Sensitivity Comparison

\begin{tabular}{|c|c|c|c|c|c|c|}
\hline analyte & $\begin{array}{l}\text { precursor } \\
\text { ion }(m / z)\end{array}$ & $\begin{array}{c}\text { production } \\
\qquad(m / z)\end{array}$ & collision voltage $(\mathrm{V})$ & calibration curve equation & $R^{2}$ & sensitivity increase (fold) \\
\hline methoprene & 311 & 191 & 12 & $y=5.0675 x+416.67$ & 0.9778 & \\
\hline kinoprene & 277 & 137 & 12 & $y=15.217 x-124.73$ & 0.9996 & \\
\hline hydroprene & 267 & 109 & 21 & $y=16.811 x+5065.5$ & 0.9960 & \\
\hline $\begin{array}{l}\text { methoprene- } \\
\text { PTAD }\end{array}$ & 454 & 242 & 21 & $y=6641.8 x-525.17$ & 0.9943 & 1310 \\
\hline $\begin{array}{l}\text { kinoprene- } \\
\text { PTAD }\end{array}$ & 452 & 242 & 21 & $y=1555.2 x+1051.7$ & 0.9991 & 102 \\
\hline $\begin{array}{l}\text { hydroprene- } \\
\text { PTAD }\end{array}$ & 442 & 242 & 21 & $y=1524.4 x+1567.8$ & 0.9920 & 91 \\
\hline
\end{tabular}


Table 2

Influence of Various Factors on Sample Stability ${ }^{a}$

\begin{tabular}{|c|c|c|c|}
\hline storage conditions & $\begin{array}{c}\text { methoprene } \\
\text { recovery }(\%) \text { and } \\
\text { SD }\end{array}$ & $\begin{array}{c}\text { kinoprene } \\
\text { recovery }(\%) \text { and } \\
\text { SD }\end{array}$ & $\begin{array}{c}\text { hydroprene } \\
\text { recovery }(\%) \text { and } \\
\text { SD }\end{array}$ \\
\hline $\begin{array}{l}\text { room temperature, scattered daylight, no methanol added, no sodium } \\
\text { azide added, foil-lined cap, amber glass vial }\end{array}$ & $\mathrm{nd}^{b}$ & nd & nd \\
\hline $\begin{array}{l}+4^{\circ} \mathrm{C} \text { in the dark, methanol added, sodium azide added, no cap lining, } \\
\text { amber glass vial }\end{array}$ & $42.5 \pm 6.7$ & $71.1 \pm 16.8$ & $53.3 \pm 8.7$ \\
\hline $\begin{array}{l}+4{ }^{\circ} \mathrm{C} \text { in the dark, methanol added, sodium azide added, foil-lined } \\
\text { cap, clear glass vial }\end{array}$ & $49.3 \pm 19.0$ & $104 \pm 57$ & $68.6 \pm 26.2$ \\
\hline $\begin{array}{l}+4{ }^{\circ} \mathrm{C} \text { in the dark, no methanol added, sodium azide added, no cap } \\
\text { lining, amber glass vial }\end{array}$ & $61.8 \pm 12.1$ & $88.9 \pm 10.2$ & $80.0 \pm 9.9$ \\
\hline $\begin{array}{l}+4^{\circ} \mathrm{C} \text { in the dark, methanol added, sodium azide added, no cap lining, } \\
\text { amber glass vial }\end{array}$ & $65.7 \pm 16.0$ & $109 \pm 37$ & $89.5 \pm 23.1$ \\
\hline
\end{tabular}

${ }^{a}$ Recoveries were normalized to the recovery of standard $10 \%$ methanol solution prepared immediately before the extraction.

$b_{\text {nd }}=$ not detected. 
Table 3

Method Limit of Detection and Quantification

\begin{tabular}{lcc}
\hline & sample LOD $(\mathbf{p g} / \mathbf{m L})$ & sample LOQ $(\mathbf{p g} / \mathbf{m L})$ \\
\hline methoprene-PTAD & 6 & 20 \\
kinoprene-PTAD & 20 & 60 \\
hydroprene-PTAD & 20 & 60 \\
\hline
\end{tabular}


Table 4

Comparison of Single Quadrupole and Tandem Quadrupole Performance ${ }^{a}$

\begin{tabular}{|c|c|c|c|}
\hline & & MRM mode & SIR mode \\
\hline $\begin{array}{l}\text { control } \\
\text { matrix }(n=3)\end{array}$ & $\begin{array}{l}\text { peak area } \\
\text { signal-to-noise ratio } \\
\text { peak area } \\
\text { signal-to-noise ratio }\end{array}$ & $\begin{array}{r}182300 \\
6330 \\
145200 \\
1360\end{array}$ & $\begin{array}{r}822100 \\
250 \\
497800 \\
90\end{array}$ \\
\hline
\end{tabular}

${ }^{a}$ Derivatized methoprene was dissolved in pure solvent (control) and extracted matrix, and 100 pg was injected on the column. For the matrix, averages of triplicate are shown. 
Table 5

Results of Methoprene Concentration Measurements at Eight Sites of the Flooded Pasture Treated with Altosand

\begin{tabular}{|c|c|c|c|c|c|}
\hline \multirow[b]{2}{*}{ site } & \multicolumn{5}{|c|}{ methoprene concentration $(\mathrm{ng} / \mathrm{mL})$ and SD } \\
\hline & day 1 & day 2 & day 3 & day 4 & day 5 \\
\hline 1 & $2.36 \pm 0.22$ & $0.224 \pm 0.047$ & $0.273 \pm 0.048$ & $0.106 \pm 0.014$ & $0.345 \pm 0.042$ \\
\hline 2 & $0.116 \pm 0.018$ & $0.198 \pm 0.010$ & $0.115 \pm 0.014$ & $0.064 \pm 0.010$ & $0.226 \pm 0.037$ \\
\hline 3 & $0.701 \pm 0.066$ & $0.153 \pm 0.007$ & $0.108 \pm 0.079$ & $0.055 \pm 0.006$ & $0.166 \pm 0.019$ \\
\hline 4 & $1.36 \pm 0.04$ & $0.412 \pm 0.042$ & $0.184 \pm 0.038$ & $0.178 \pm 0.022$ & $0.169 \pm 0.022$ \\
\hline 5 & $1.32 \pm 0.07$ & $0.094 \pm 0.010$ & $2.26 \pm 0.27$ & $0.057 \pm 0.002$ & $2.59 \pm 0.12$ \\
\hline 6 & $0.469 \pm 0.019$ & $0.125 \pm 0.005$ & nd $\quad a$ & $0.054 \pm 0.007$ & $0.054 \pm 0.006$ \\
\hline 7 & $2.62 \pm 0.17$ & $0.040 \pm 0.005$ & $0.299 \pm 0.000$ & nd & $0.050 \pm 0.009$ \\
\hline 8 & $0.469 \pm 0.019$ & $0.090 \pm 0.009$ & $2.071 \quad b$ & nd & $0.032 \pm 0.006$ \\
\hline
\end{tabular}

$a_{\text {nd }=\text { not detected. }}$

${ }^{b} N=2$. 